\title{
Solids: Exciting Research Should Be Accessible to the General Public-A Plea for a New Open Access Journal
}

\author{
Guido Kickelbick (1) \\ Inorganic Solid-State Chemistry, Saarland University, Campus Building C4 1, 66123 Saarbrücken, Germany; \\ guido.kickelbick@uni-saarland.de; Tel.: +49-681-302-70651
}

Received: 16 December 2020; Accepted: 17 December 2020; Published: 21 December 2020

Solid-state sciences continue to be one of the key pillars of scientific and technological progress in our society. Future challenges in energy production and use, materials for longer lasting products, health care related materials, or those for exploring space have their birthplace in the lab of solid-state scientists. Often only small variations on the atomistic scale in such materials have large consequences in their macroscopic properties. Intriguing effects such as magnetism, pyroelectricity, thermoelectricity, superconductivity, or optical and electronic properties are examples of how fundamental knowledge of the solid-state phenomena can be transformed in high-tech materials. Many times, we can only understand the working principle if we look very closely into the atomistic world and into the respective atomistic ordering of the material. Thus, when dealing with the solid-state, we must target the fundamentals of the materials to show the fascination of this topic not only to colleagues but also to students and the public. Therefore, with this journal we are addressing a field at the borderline between fundamental science, technology, and society. While in the past many scientific insights were produced in a single lab, interdisciplinary work is now promoted to understand materials and to develop new approaches to solid-state properties. In particular, the borderlines between the disciplines are interesting playing fields in which science develops dramatically.

Solids, an open-access international journal by MDPI (Basel, Switzerland), focuses on the broad field of solid-state materials. It is a forum for outstanding scientific results, the discussion of new ideas and a detailed view on both the fundamentals and applications of the solid-state. The journal publishes rigorously peer-reviewed original research papers, review articles, short communications, and opinion pieces on emerging research topics. We also welcome negative results as they may also advance the community. Thus, we explicitly encourage all authors to communicate them. We are committed to the education of young scientists and therefore particularly welcome contributions carrying the fascination of solid-state materials to students. Special Issues on selected scientific topics will multifacetedly illuminate current trends in science, thus raising the interest of more scientists in the field.

Both the editorial board and the journal staff are committed to making Solids the leading open access journal in the field of solid-state research. Committed to the scientific community, only articles of interest to a broad readership will be published that meet the high scientific standards of the reviewers and of the editorial board. Following the open-access policy, all articles in Solids are published under the terms of the Creative Commons Attribution License. Solids is available free of charge to readers around the world, and copyright remains with the author(s).

On behalf of the entire Editorial Board, I invite you to submit your exciting work and proposals for Special Issues to Solids, and I look forward to your contributions. Together we will develop a journal that will become a central building block for knowledge within our community. Let's make it happen!

Conflicts of Interest: The author declares no conflict of interest. 


\section{Short Biography of Author}

Guido Kickelbick holds a chair of Inorganic Solid-State Chemistry at the Saarland University (Germany). He studied chemistry at the University of Würzburg (Germany) and carried out his Ph.D. thesis in the group of Ulrich Schubert at the University of Würzburg and the Vienna University of Technology on sol-gel derived surface-modified metal oxo clusters. After receiving his Ph.D. degree in 1997, he was awarded an Erwin-Schrödinger post-doctoral fellowship with Krzysztof Matyjaszewski at the Center for Macromolecular Engineering at the Carnegie Mellon University in Pittsburgh (USA) on the application of controlled radical polymerization in the formation of hybrid materials. In 1998, he returned to Vienna University of Technology, where he carried out his habilitation until 2003. At the end of 2003, he was promoted to the position of Associate Professor at Vienna University of Technology. In 2009, he accepted the call to a chair of Inorganic Solid-State Chemistry at Saarland University. His fields of research are hybrid materials and nanocomposites as well as surface-functionalized nanoparticles, with a particular focus on the combination of organic polymers with inorganic components. Recent contributions additionally address mechanochemistry and continuous synthesis of solid-state materials. Guido Kickelbick published more than 200 papers on different aspects of inorganic, polymer, and materials chemistry. He authored one textbook and edited several books.

Publisher's Note: MDPI stays neutral with regard to jurisdictional claims in published maps and institutional affiliations.

(C) 2020 by the author. Licensee MDPI, Basel, Switzerland. This article is an open access article distributed under the terms and conditions of the Creative Commons Attribution (CC BY) license (http://creativecommons.org/licenses/by/4.0/). 